\title{
Is a Non-Caloric Sweeteners-Free Diet Good To Treat Functional Gastrointestinal Disorder Symptoms? A Randomized Controlled Trial
}

\section{Viridiana Montsserrat Mendoza-Martínez}

General Hospital of Mexico: Hospital General de Mexico Dr Eduardo Liceaga

\section{Mónica Rocío Zavala-Solares}

La Salle University

\section{Aranza Jhosadara Espinosa-Flores}

General Hospital of Mexico Dr Eduardo Liceaga: Hospital General de Mexico Dr Eduardo Liceaga

\section{Karen Lorena León-Barrera}

General Hospital of Mexico Dr Eduardo Liceaga: Hospital General de Mexico Dr Eduardo Liceaga

\section{Raúl Alcántara-Suárez}

General Hospital of Mexico Dr Eduardo Liceaga: Hospital General de Mexico Dr Eduardo Liceaga José Damian Carrillo-Ruíz

General Hospital of Mexico Dr Eduardo Liceaga: Hospital General de Mexico Dr Eduardo Liceaga Galileo Escobedo

General Hospital of Mexico Dr Eduardo Liceaga: Hospital General de Mexico Dr Eduardo Liceaga Marcela Esquivel-Velázquez

General Hospital of Mexico Dr Eduardo Liceaga: Hospital General de Mexico Dr Eduardo Liceaga Guillermo Melendez-Mier

General Hospital of Mexico Dr Eduardo Liceaga: Hospital General de Mexico Dr Eduardo Liceaga Nallely Bueno-Hernández ( $\square$ nallely_bh5@yahoo.com.mx )

General Hospital of Mexico Dr Eduardo Liceaga: Hospital General de Mexico Dr Eduardo Liceaga https://orcid.org/0000-0002-3961-0987

\section{Research}

Keywords: Non-Caloric Sweeteners, Sucralose, Functional Gastrointestinal Disorders, Diet, Irritable Bowel Syndrome, Gastroesophageal Reflux Disease.

Posted Date: August 3rd, 2021

DOI: https://doi.org/10.21203/rs.3.rs-741222/v1 
License: (c) (i) This work is licensed under a Creative Commons Attribution 4.0 International License. Read Full License

Version of Record: A version of this preprint was published at Nutrients on March 5th, 2022. See the published version at https://doi.org/10.3390/nu14051095. 


\section{Abstract}

\section{Background}

A diet containing Non-Caloric Sweeteners (NCS) is used to reduce calorie intake and blood sugar peaks in overweight and obese subjects. Nevertheless, some animal studies suggest that NCS consumption may increase Functional Gastrointestinal Disorder symptoms (FGDs); however, there are scant clinical trials in humans. The aim of the study was to compare the effect of consuming a diet containing NCS (c-NCS) versus a Non-Caloric Sweetener-free diet (NCS-f) on FGDs in adult volunteers.

\section{Methods}

This was a randomized, controlled, parallel-group study using two different diets for five weeks: diet cNCS contained $50-100 \mathrm{mg}$ /day NCS ( $80 \%$ sucralose and $20 \%$ aspartame, acesulfame K, and saccharin); NCS-f diet contained less than $10 \mathrm{mg} /$ day NCS. FGDs were recorded according to the Rome III criteria, gastrointestinal symptom questionnaire, Bristol scale, food frequency questionnaire, and consumption questionnaire at the beginning (PreTx) and at the end (PostTx) of the study by a gastroenterologist and a nutritionist. This study conducted according to the CONSORT guidelines and it was registered at clinicaltrials.gov (identifier code: NCT04129762).

\section{Results}

Participants were more often women than men in both groups (59\% and $62 \%)$, with a median age of 22 years. FGDs were similar in both groups at the beginning of the study (PreTx) but significantly increased in the diet c-NCS group after five weeks (PostTx). The percentage of participants with diarrhea (PreTx $=19 \%$ versus PstTx $=56 \% ; p=0.02$ ), post-prandial discomfort (PreTx $=9 \%$ versus $P s t T x=39 \% ; p=0.02$ ), constipation (PreTx $=30 \%$ versus PostT $x=56 \% ; p<0.01$ ), and burning or retrosternal pain (PreTx $=13 \%$ versus PostTx $=33 \% ; p<0.01$ ) significantly increased in the diet c-NCS group. Conversely, abdominal pain (PreTx $=15 \%$ versus PostTx $=3 \% ; p=0.04$ ), post-prandial discomfort (PreTx $=26 \%$ versus PostT $x=6 \%$; $p=0.02$ ), burning or retrosternal pain (PreTx $=15 \%$ versus Post $T x=0 \% ; p=0.02$ ), early satiety (PreTx $=18 \%$ versus PostTx $=3 \% ; p<0.01$ ), and epigastric pain (PreT $x=38 \%$ versus PostTx $=3 \% ; p<0.01$ ) significantly decreased in the NCS-f diet group.

\section{Conclusion}

This study shows that diet c-NCS associates with increased FGDs including diarrhea, post-prandial discomfort, constipation, and burning or retrosternal pain. Interestingly, NCS-f diet concurs with decreased FGDs such as abdominal pain, post-prandial discomfort, burning or retrosternal pain, early satiety, and epigastric pain. A NCS-f diet could be a complementary strategy to alleviate FGDs.

Trial registration: The ethics committee of the hospital approved this study with the registration number DI/19/301/03/020. This trial was registered at clinicaltrials.gov (identifier code: NCT04129762). 


\section{Background}

A diet containing Non-Caloric Sweeteners (c-NCS) is widely used to reduce calorie intake and blood sugar peaks in overweight and obese individuals. For this reason, the amount of foods and beverages containing Non-Caloric Sweeteners (NCS) has increased in the last few years. Sucralose, aspartame, acesulfame potassium (K), and saccharin are the most widely used NCS that have been approved by the United States Food and Drug Administration (FDA) [1] [2] [3].

In Latin America, the number of subjects consuming NCS is as high as 70\% [4]. Nevertheless, some studies have shown that NCS consumption concurs with Functional Gastrointestinal Disorder symptoms (FGDs), since the amount of unabsorbed sweetener can be metabolized by gut microbiota, triggering changes in intestinal habit. Moreover, NCS consumption has been associated with altered secretion of hormones able to regulate intestinal transit such as glucagon-like peptide-1 (GLP-1), gastric inhibitory polypeptide (GIP), peptide YY (PYY), and cholecystokinin (CCK); however, the role of NCS in gastrointestinal pathogenesis remains uncertain [5] [6] [7] [8].

FGDs, such as irritable bowel syndrome (IBS), functional dyspepsia, or functional constipation, diarrhea, and gastroesophageal reflux disease (GERD) are recurrent conditions that account for at least $30 \%$ of referrals to gastroenterologists [9] [10] [11].

A study assessing gastrointestinal symptoms in experimental animals showed that rabbits fed 750$1000 \mathrm{mg} / \mathrm{kg} /$ day sucralose develop gastrointestinal symptoms including perianal soiling, scouring, and cecal enlargement as compared to controls [12] [13].

This evidence suggests potential deleterious actions of NCS consumption in the development of FGDs; nevertheless, there are scarce clinical studies in human populations.

The aim of the study was to compare the effect of consuming a diet c-NCS versus a Non-Caloric Sweetener-free (NCS-f) diet on FGDs in adult volunteers.

\section{Material And Methods}

\section{Trial design}

This was a randomized, controlled, parallel-group study conducted according to the Consolidated Standards of Reporting Trials (CONSORT) guidelines [14]. This trial was registered at clinicaltrials.gov (identifier code: NCT04129762).

\section{Ethical considerations}

The ethics committee of the hospital approved this study with the registration number DI/19/301/03/020. All participants signed the informed consent and received an explanation of the purpose and procedures used in the study. 


\section{Eligibility criteria for participants}

Inclusion criteria were women or men aged 18 to $35 \mathrm{yrs}$ old, who agreed not to consume alcohol or NCS during the study. The exclusion criteria included participants with previous diagnosis of diabetes, hypertension, and metabolic diseases. Pregnant or lactating women were also excluded from the study. Participants were enlisted at the Laboratory of Proteomics and Metabolomics, Research Division at the General Hospital of Mexico Dr. Eduardo Liceaga.

\section{Interventions}

Each volunteer was randomly assigned to two types of diet for five weeks: diet c-NCS containing 50-100 $\mathrm{mg} /$ day NCS ( $80 \%$ sucralose and $20 \%$ aspartame, acesulfame K, and saccharin), and NCS-f diet that contained $<10 \mathrm{mg} /$ day NCS. Volunteers in the NCS-f diet group received a list of all foods and drinks available in the market that contained NCS and sucralose liquid (48 to $96 \mathrm{mg}$ ) for use in their drinks. The volunteers in NCS-f diet had the same list and were instructed to avoid their consumption for the entire time of the study. FGDs were registered at the beginning (PreTx) and at the end (PostTx) of the study.

\section{Outcomes}

NCS consumption was measured using a Food Frequency Questionnaire (FFQ) and a NCS Consumption Questionnaire (SCQ), previously validated by our group in order to estimate the adherence to treatment and consumption of sweeteners [15]. Also, FGDs were registered at PreTx and at PostTx according to the Rome III criteria, gastrointestinal questionnaire symptoms, and Bristol scale by a gastroenterologist and a nutritionist. The gastrointestinal questionnaire symptoms evaluated the development of FGDs as early satiety, constipation, diarrhea, burning or retrosternal pain, epigastric pain, abdominal pain, and postprandial discomfort, at the beginning and at the end of the study. The participants with stool consistency type 1 or 2 according to the Bristol scale were diagnosed with constipation. Subjects with Bristol type 3 or 4 were considered to have normal evacuations, and volunteers with Bristol type 5 to 7 were considered to have diarrhea. Body composition was measured by electrical bioimpedance (RJL Quantum IV system, RJL Systems Inc. Clinton Township MI, USA). Anthropometric data such as weight (Weighing Machine, MS 50 SECA; Hamburg Germany), height (Scale, MD 213 SECA; Hamburg Germany), waist and hip circumferences (Metric Tape W606 Lufkin; CdMx Mexico) were measurement by a nutritionist.

\section{Sample size and randomization}

The sample size calculation was performed with the GPower v.3.1 9.2 program, expecting an effect size of 0.4 , with an alpha error of 0.05 and a power of $80 \%$, resulting in a sample size of 30 participants per group. Nevertheless, the number of participants in the diet c-NCS group was increased in order to decrease intervention bias.

The randomization scheme was generated by using the Website randomization.com (http://www.randomization.com) and the rationalization scheme was by blocks ( 6 blocks of 5 patients 
each one). Consecutive numbers were randomized to different kinds of diets and then assigned to the patients.

\section{Statistics}

Normality of data distribution was assessed using the Kolmogorov Smirnov test. T-Test, Paired T-Test, and $\mathrm{X}^{2}$ test were used to compare intervention groups at the beginning and at the end of the study. A $P$ value $<0.05$ was considered as statistically significant. SPSS Statistics 21 was used for the statistical analysis.

\section{Results}

One hundred and thirty-seven participants were included in the study from October 2019 to June 2020 and randomly assigned to diet c-NCS or NCS-free diet. Ninety-five participants completed the study, specifically, 34 volunteers in the NCS-free diet group and 61 volunteers in the diet c-NCS group. Figure 1 shows a flow chart of the study according to the CONSORT guidelines.

Table 1 shows the baseline characteristics of the population. Participants were more often women than men in both groups (59\% and $62 \%$ ), with a median age of $22 \pm 3.2 \mathrm{yrs}$ in NCS-f diet group, and $22 \pm 3.1 \mathrm{yrs}$ in diet c-NCS group. There were no significant differences between groups for weight ( $64.9 \pm 12.71 \mathrm{vs}$. $64.9 \pm 12.77 ; P=0.98)$, waist-to-hip ratio $(0.81 \pm 0.67$ vs. $0.81 \pm 0.65 ; P=052)$, and body mass index $(24.16 \pm 3.8$ vs. $23.9 \pm 3.1 ; P=0.75)$ at the beginning of the study. Consumption of carbohydrates, proteins, lipids, and calories was not different between groups at the beginning of the study. Moreover, the amount and type of NCS consumed were similar in both groups at the beginning of the study (Table 1). 
Table 1

Baseline characteristics of the volunteers.

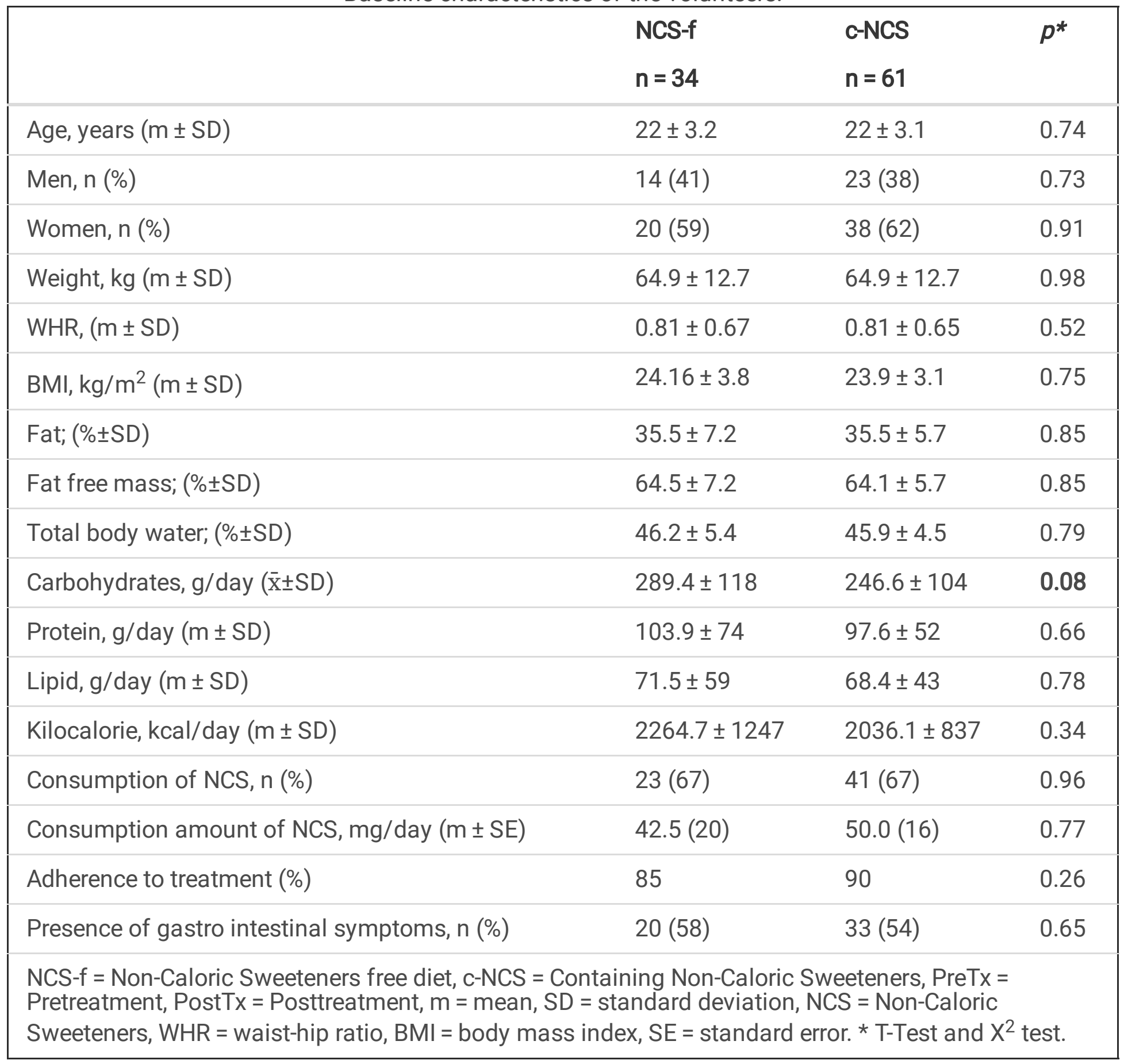

At the end of the study, in the NCS-f diet group, NCS (mg/day) consumption decreased as compared to baseline (PreTx $=42.5 \pm 20.9$ vs. PostTx $=2.6 \pm 1.7 ; P=0.06)$ in NCS-free diet group, whereas it tended to increase in the diet c-NCS group (PreTx $=50.03 \pm 16$ vs. PostTx $=74.2 \pm 3.3 ; P=0.15$ ) without reaching significant differences (Table 2). 
Table 2

Differences between diet groups (NCS-f and c-NCS) at the beginning (PreTx) and at the end (PostTx) of dietary interventions.

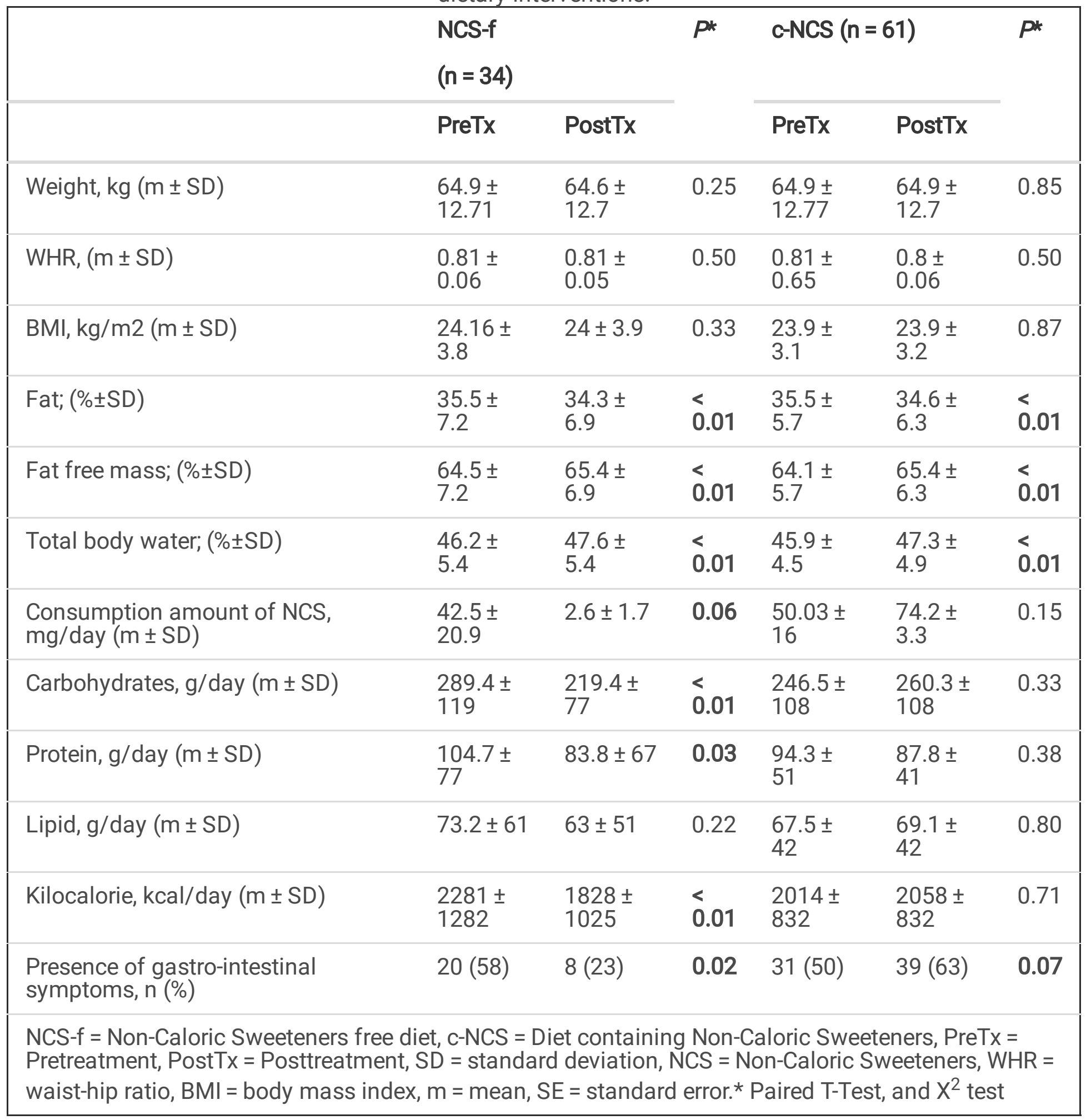

\section{Gastrointestinal symptoms}

In the diet c-NCS group, the vast majority of FGDs increased after five weeks of dietary intervention. Specifically, the percentage of participants with diarrhea (PreTx $=19 \%$ to PostTx $=56 \% ; P=0.02$ ), postprandial discomfort (PreTx $=9 \%$ to PostTx $=39 \% ; P=0.02)$, constipation (PreTx $=30 \%$ to PostTx $=56 \% ; P$ 
$<0.01$ ), and burning or retrosternal pain (PreTx $=13 \%$ to PostTx $=33 \% ; P<0.01$ ) significantly increased at the end of the study as compared to baseline (Fig. 2A).

Participants in the NCS-f diet group showed significant decreases in all FGDs at the end of the study, especially, abdominal pain (PreTx $=15 \%$ to PostTx $=3 \% ; P=0.04$ ), post-prandial discomfort (PreTx $=26 \%$ to PostTx $=6 \% ; P=0.02$ ), burning or retrosternal pain (PreTx $=15 \%$ to PostTx $=0 \% ; P=0.02$ ), early satiety (PreTx $=18 \%$ to PostTx $=3 \% ; P<0.01)$, and epigastric pain (PreTx $=38 \%$ to PostTx $=3 \% ; P<0.01)$ (Fig. 2B).

\section{Dietary effects}

Weight, waist-to-hip ratio, and body mass index showed no significant changes after dietary interventions in both groups. In the NCS-f diet group, consumption of carbohydrates (PreTx $=289.4 \pm 119$ vs. PostTx $=$ $219.4 \pm 77 ; P=0.001)$ and energy $($ PreTx $=2281.9 \pm 1282$ vs. PostTx $=1828.2 \pm 1025 ; P=0.007)$ significantly decreased after diet. Conversely, in the diet c-NCS group, consumption of carbohydrates (PreTx $=246.5 \pm 108$ vs. PostTx $=260.3 \pm 108 ; P=0.33)$, lipids (PreTx $=67.5 \pm 42$ vs. PostTx $=69.1 \pm 42 ; P$ $=0.80)$, and energy (PreTx $=2014.3 \pm 832$ vs. PostTx $=2058.3 \pm 832 ; P=0.71)$ tended to increase without reaching significant differences (Table 2).

Finally, volunteers from both groups exhibited a significant decrease in fat percentage after dietary interventions (NCS-f: PreTx $=35.5 \pm 7.2$ vs. PostTx $=34.3 \pm 6.9 ; p<0.01$, and c-NCS: PreTx $=35.5 \pm 5.7$ vs. PostTx $=34.6 \pm 6.3 ; p<0.01)$. Additionally, subjects from both groups showed significant increases in free fat mass (NCS-f: PreTx $=64.5 \pm 7.2$ vs. PostTx $=65.4 \pm 6.9 ; p<0.01$ and c-NCS: PreTx $=64.1 \pm 5.7$ vs. PostTx $=65.4 \pm 6.3 ; p<0.01$ ) and total body water (NCS-f: PreTx $=46.2 \pm 5.4$ vs. final $=47.6 \pm 5.4 ; p<0.01$ and c-NCS: PreTx $=45.9 \pm 4.5$ vs.PostTx $=47.3 \pm 4.9 ; p<0.01)$ at the end of dietary interventions (Table 2$)$.

\section{Discussion}

The effects of NCS on FGDs are scantly studied and available data are predominantly from animal studies. To the best of our knowledge, this is the first study in human beings that evaluates the development of FGDs in response to a diet containing NCS, particularly sucralose. Emerging evidence suggests that FGDs occur as a consequence of changes in gut microbiota and hormones that regulate gastrointestinal motility. It is worth mentioning that despite numerous studies have consistently shown the deleterious effects of NCS on health, their consumption as part of the diet is increasing worldwide [4]. This phenomenon may be partially explained since many developing countries are experiencing transitions from a Mediterranean diet to a Western diet that contains more additives in ultra-processed food and drinks (UPFDs) [3] [16] [17] [18]. For instance, our results show that basally more than $60 \%$ of participants frequently consumed any kind of NCS, an amount significantly higher than that informed in a cross-sectional study in the USA, wherein $41.4 \%$ of adults reported often NCS consumption [19]. It is worth mentioning that the vast majority of the study participants did not know they consumed NCS because UPFDs labels did not mention the word "light". When reviewed ingredients mentioned in the FFQ 
and SCQ, several foods and drinks contained NCS. In fact, all participants consumed, on average, 42-50 $\mathrm{mg} /$ day NCS before the study enrollment.

This prospective study demonstrates that NCS-f diet group decreases the presence of FGDs in young people, especially, early satiety, burning or retrosternal pain, epigastric pain, abdominal pain, and postprandial discomfort. In fact, at the beginning of the study, more than $50 \%$ of participants had at least one gastrointestinal symptom, which in turn significantly decreases after five weeks of NCS-free diet. In this group, epigastric pain (35\%) and postprandial discomfort (20\%) were the leading symptoms showing clear decreases. This phenomenon may be explained since some NCS appears to cause increases in incretins such as GLP-1, GIP, PYY, and CCK. GLP-1 decreases motility in the antro-duodeno-jejunal region and inhibits the migrating motility complex in healthy controls and IBS patients. CCK delays gastric emptying and GIP can also slow gastric emptying [20] [21], PYY causes delayed intestinal transit [13]. Interestingly, acesulfame-K in combination with fructose might cause slow gastric emptying by increasing motilin secretion that in turn promotes satiety, just five minutes after NCS administration [22]. Thus, removal of NCS from the diet may decrease incretin secretion, promoting gastrointestinal motility and gastric emptying, which in turn could be able to improve epigastric pain and discomfort after food or drink consumption.

Another phenomenon captured in our study is the significant increase in bowel habit alterations in the diet c-NCS group, especially, diarrhea, constipation, and post-prandial discomfort. A possible hypothesis to explain these findings involves changes in the intestinal environment caused by NCS consumption, including decreased strictly anaerobic bacteria, potential inflammation, and increased gastrointestinal motility, which allow expansion of pathogenic bacteria such as Enterobacteriaceae and Clostridium leptum [23].

Several in vitro and in vivo studies reported an association of sucralose ingestion with a higher amount of commensal strain subpopulations in gut microbiota. Some of these bacteria associate with diarrhea, constipation, or both, as a consequence of changes in intestinal permeability [24] [25] [26].

Abou-Donia et al. showed that sucralose administration for 12 weeks had numerous adverse effects on the intestine of Sprague-Dawley male rats, including elevation in fecal $\mathrm{pH}$ that in turn may associate with changes in the absorption of nutrients and drugs from the gastrointestinal tract. In the same study, the authors found a decrease in beneficial anaerobic bacteria, such as bifidobacteria, lactobacilli, and Bacteroides [27]. It is worth mentioning that the use of Bifidobacterium and Lactobacillus have benefits in the treatment of diarrhea and amelioration of IBS symptoms such as flatulence, stool pressure, pain, and a sensation of incomplete bowel movements. The use of Bacteroides species also benefit patients by preventing digestive tract colonization from other potential pathogens [28] [29] [30].

Nowadays, modifications of gut microbiota by reducing NCS intake are crucial; nevertheless, there are few clinical studies, particularly in humans. One of the most important is the study by Suez et al. in 2014, wherein they found in 172 individuals a positive correlation between NCS consumption and the Enterobacteriaceae family, the Deltaproteobacteria class, and the Actinobacteria phylum [7] [31] [24]. 
Disruption of the intestinal microbiota balance by NCS may potentially interfere with numerous essential gut functions, including normal immune responses, pathogen control, gastrointestinal motility, and nutrient metabolism.

Our results show that NCS-f diet improves FGDs, even though patients from both groups displayed a similar proportion of gastrointestinal symptoms at the beginning of the study. Furthermore, these changes did not depend on body composition (fat, fat-free mass, and total body water percentage), since no relevant clinical changes were found.

More studies are needed using relevant doses of sweeteners in a biological context and exploring the possible molecular mechanisms through which NCS affects gut microbiota profile and neuropeptides such as GLP-1, GIP, PYY, CCK, and vasoactive intestinal peptide.

This study has some limitations. First of all, we enrolled a small number of patients with FGDs diagnoses. In the second place, the study population appears very young since the FGDs prevalence increases at the age of $30 \mathrm{yrs}$. In the third place, the unbalanced number of male and female participants should be noted since sex hormone profiles may differentially affect the presence of gastrointestinal symptoms. Finally, other dietary aspects such as fasting periods, sugar, and fever consumption were not controlled in the study population.

\section{Conclusions}

This study shows that a NCS-free diet might be of benefit to alleviate numerous FGDs such as abdominal pain, post-prandial discomfort, burning or retrosternal pain, early satiety, and epigastric pain. On the contrary, a diet containing NCS appears to increase diarrhea, post-prandial discomfort, constipation, and burning or retrosternal pain, a notion that should be taken into account by gastroenterologists and nutritionists in the treatment of FGDs.

\section{List Of Abbreviations}

$\mathrm{BMI}$, body mass index

CCK, cholecystokinin

CONSORT, Consolidated Standards of Reporting Trials

FGDs, gastrointestinal disorder symptoms

GERD, gastroesophageal reflux disease

GLP-1, glucagon-like peptide 1

GIP, gastric inhibitory polypeptide 
IBS, irritable bowel syndrome

NCS, non-caloric sweeteners

NCS-f, non-caloric sweeteners free

c-NCS, containing non-caloric sweeteners

PYY, peptide YY

PreTx, pretreatment

PostTx, posttreatment

SD, standard deviation

SE, standard error

UPFDs, ultra-processed food and drinks

WHR, waist-hip ratio

\section{Declarations}

Ethics approval and consent to participate: The ethics committee of the hospital approved this study with the registration number DI/19/301/03/020. All participants signed the informed consent and received an explanation of the purpose and procedures used in the study.

Consent for publication: All authors approved the publication of the manuscript in the Nutrition Journal.

Availability of data and materials: We have made publicly and freely available without restriction the data described in the manuscript, at:

https://www.dropbox.com/s/3riwj6oz7lprvqy/Base\%20de\%20Datos\%2019-06-18_2.sav?dl=0

Competing interests: The authors declare no potential conflicts of interest.

Funding: This research was supported by grant from National Council on Science and Technology (CONACYT) registered with the funding number 261575.

Authors' contributions: NBH, GMM and VMMM; performed writing original draft, conceptualization and formal analysis. MRZS, JDCR and GE; performed writing-review and editing. AJEF, KLDLB, RAS and MEV; development of methodology and investigation. GMM and GE; funding acquisition.

Acknowledgements: We the thanks to staff and patients at the General Hospital of Mexico "Dr. Eduardo Liceaga" for all contributions to the study. To Ernesto Roldan-Valadez for all the facilities provided for data analysis. 


\section{References}

1. Rogers PJ. The role of low-calorie sweeteners in the prevention and management of overweight and obesity: evidence v. conjecture. Proc Nutr Soc. 2018;77:230-8.

2. Sambra V, López-Arana S, Cáceres P, Abrigo K, Collinao J, Espinoza A, Valenzuela S, Carvajal B, Prado G, Peralta R, Gotteland M: Overuse of Non-caloric Sweeteners in Foods and Beverages in Chile: A Threat to Consumers' Free Choice? Front Nutr 2020, 7:68.

3. Walbolt J, Koh Y. Non-nutritive Sweeteners and Their Associations with Obesity and Type 2 Diabetes. J Obes Metab Syndr. 2020;29:114-23.

4. Martyn D, Darch M, Roberts A, Lee HY, Yaqiong Tian T, Kaburagi N, Belmar P. Low-/No-Calorie Sweeteners: A Review of Global Intakes. Nutrients 2018, 10.

5. Bueno-Hernández N, Vázquez-Frías R, Abreu YAAT, Almeda-Valdés P, Barajas-Nava LA, CarmonaSánchez RI, Chávez-Sáenz J, Consuelo-Sánchez A, Espinosa-Flores AJ, Hernández-Rosiles V, et al. Review of the scientific evidence and technical opinion on noncaloric sweetener consumption in gastrointestinal diseases. Rev Gastroenterol Mex (Engl Ed). 2019;84:492-510.

6. Bueno-Hernandez N, Jiménez-Cruz BL, Zavala-Solares M, Meléndez-Mier G. Association of Natural and Artificial Nonnutritive Sweeteners on Gastrointestinal Disorders: A Narrative Review. Journal of Nutrition Food Sciences. 2018;08:1-8.

7. Ruiz-Ojeda FJ, Plaza-Díaz J, Sáez-Lara MJ, Gil A. Effects of Sweeteners on the Gut Microbiota: A Review of Experimental Studies and Clinical Trials. Adv Nutr. 2019;10:31-s48.

8. Chirila I, Morariu ID, Barboi OB, Drug VL. The role of diet in the overlap between gastroesophageal reflux disease and functional dyspepsia. Turk J Gastroenterol. 2016;27:73-80.

9. Shivaji UN, Ford AC. Prevalence of functional gastrointestinal disorders among consecutive new patient referrals to a gastroenterology clinic. Frontline Gastroenterol. 2014;5:266-71.

10. Black CJ, Drossman DA, Talley NJ, Ruddy J, Ford AC. Functional gastrointestinal disorders: advances in understanding and management. Lancet. 2020;396:1664-74.

11. Huerta-Iga F, Bielsa-Fernández MV, Remes-Troche JM, Valdovinos-Díaz MA, Tamayo-de la Cuesta JL. Diagnosis and treatment of gastroesophageal reflux disease: recommendations of the Asociación Mexicana de Gastroenterología. Rev Gastroenterol Mex. 2016;81:208-22.

12. Kille JW, Tesh JM, McAnulty PA, Ross FW, Willoughby CR, Bailey GP, Wilby OK, Tesh SA. Sucralose: assessment of teratogenic potential in the rat and the rabbit. Food Chem Toxicol. 2000;38(Suppl 2):43-52.

13. Spencer M, Gupta A, Dam LV, Shannon C, Menees S, Chey WD. Artificial Sweeteners: A Systematic Review and Primer for Gastroenterologists. J Neurogastroenterol Motil. 2016;22:168-80.

14. Moher D, Hopewell S, Schulz KF, Montori V, Gøtzsche PC, Devereaux PJ, Elbourne D, Egger M, Altman DG. CONSORT 2010 explanation and elaboration: updated guidelines for reporting parallel group randomised trials. Int J Surg. 2012;10:28-55. 
15. Bueno-Hernandez N, Alcántara-Suárez R, Pérez-Castañeda M, Hernández-León YA, Ruiz-Barranco A, Escobedo G, Islas-Andrade S, Melendez G. Content Validity and Reliability of a Food Frequency Questionnaire with Intense Sweeteners (FFQIS) in a Hispanic Population. Journal of Nutrition Food Sciences. 2018;08:1-4.

16. Alexandratos N. The Mediterranean diet in a world context. Public Health Nutr. 2006;9:111-7.

17. García-Montero C, Fraile-Martínez O, Gómez-Lahoz AM, Pekarek L, Castellanos AJ, NogueralesFraguas F, Coca S, Guijarro LG, García-Honduvilla N, Asúnsolo A, et al: Nutritional Components in Western Diet Versus Mediterranean Diet at the Gut Microbiota-Immune System Interplay. Implications for Health and Disease. Nutrients 2021, 13.

18. Organization WH. Safety evaluation of certain contaminants in food. Prepared by the Sixty-fourth meeting of the Joint FAO/WHO Expert Committee on Food Additives (JECFA). FAO Food Nutr Pap. 2006;82:1-778.

19. Sylvetsky AC, Jin Y, Clark EJ, Welsh JA, Rother KI, Talegawkar SA. Consumption of Low-Calorie Sweeteners among Children and Adults in the United States. J Acad Nutr Diet. 2017;117:441-8.e442.

20. Edholm T, Degerblad M, Grybäck P, Hilsted L, Holst JJ, Jacobsson H, Efendic S, Schmidt PT, Hellström PM. Differential incretin effects of GIP and GLP-1 on gastric emptying, appetite, and insulin-glucose homeostasis. Neurogastroenterol Motil 2010, 22:1191-200, e1315.

21. Hellström PM, Näslund E, Edholm T, Schmidt PT, Kristensen J, Theodorsson E, Holst JJ, Efendic S. GLP-1 suppresses gastrointestinal motility and inhibits the migrating motor complex in healthy subjects and patients with irritable bowel syndrome. Neurogastroenterol Motil. 2008;20:649-59.

22. Meyer-Gerspach AC, Biesiekierski JR, Deloose E, Clevers E, Rotondo A, Rehfeld JF, Depoortere I, Van Oudenhove L, Tack J. Effects of caloric and noncaloric sweeteners on antroduodenal motility, gastrointestinal hormone secretion and appetite-related sensations in healthy subjects. Am J Clin Nutr. 2018;107:707-16.

23. Nettleton JE, Reimer RA, Shearer J. Reshaping the gut microbiota: Impact of low calorie sweeteners and the link to insulin resistance? Physiol Behav. 2016;164:488-93.

24. Suez J, Korem T, Zilberman-Schapira G, Segal E, Elinav E. Non-caloric artificial sweeteners and the microbiome: findings and challenges. Gut Microbes. 2015;6:149-55.

25. Tlaskalová-Hogenová H, Stěpánková R, Kozáková H, Hudcovic T, Vannucci L, Tučková L, Rossmann P, Hrnčír T, Kverka M, Zákostelská Z, et al. The role of gut microbiota (commensal bacteria) and the mucosal barrier in the pathogenesis of inflammatory and autoimmune diseases and cancer: contribution of germ-free and gnotobiotic animal models of human diseases. Cell Mol Immunol. 2011;8:110-20.

26. Mujagic Z, Ludidi S, Keszthelyi D, Hesselink MA, Kruimel JW, Lenaerts K, Hanssen NM, Conchillo JM, Jonkers DM, Masclee AA. Small intestinal permeability is increased in diarrhoea predominant IBS, while alterations in gastroduodenal permeability in all IBS subtypes are largely attributable to confounders. Aliment Pharmacol Ther. 2014;40:288-97. 
27. Abou-Donia MB, El-Masry EM, Abdel-Rahman AA, McLendon RE, Schiffman SS. Splenda alters gut microflora and increases intestinal p-glycoprotein and cytochrome p-450 in male rats. J Toxicol Environ Health A. 2008;71:1415-29.

28. Skrzydło-Radomańska B, Prozorow-Król B, Cichoż-Lach H, Majsiak E, Bierła JB, Kosikowski W, Szczerbiński M, Gantzel J, Cukrowska B: The Effectiveness of Synbiotic Preparation Containing Lactobacillus and Bifidobacterium Probiotic Strains and Short Chain Fructooligosaccharides in Patients with Diarrhea Predominant Irritable Bowel Syndrome-A Randomized Double-Blind, PlaceboControlled Study. Nutrients 2020, 12.

29. Guandalini S. Probiotics for prevention and treatment of diarrhea. J Clin Gastroenterol. 2011;45(Suppl):149-53.

30. Wexler HM. Bacteroides: the good, the bad, and the nitty-gritty. Clin Microbiol Rev. 2007;20:593-621.

31. Suez J, Korem T, Zeevi D, Zilberman-Schapira G, Thaiss CA, Maza O, Israeli D, Zmora N, Gilad S, Weinberger $A$, et al. Artificial sweeteners induce glucose intolerance by altering the gut microbiota. Nature. 2014;514:181-6.

\section{Figures}




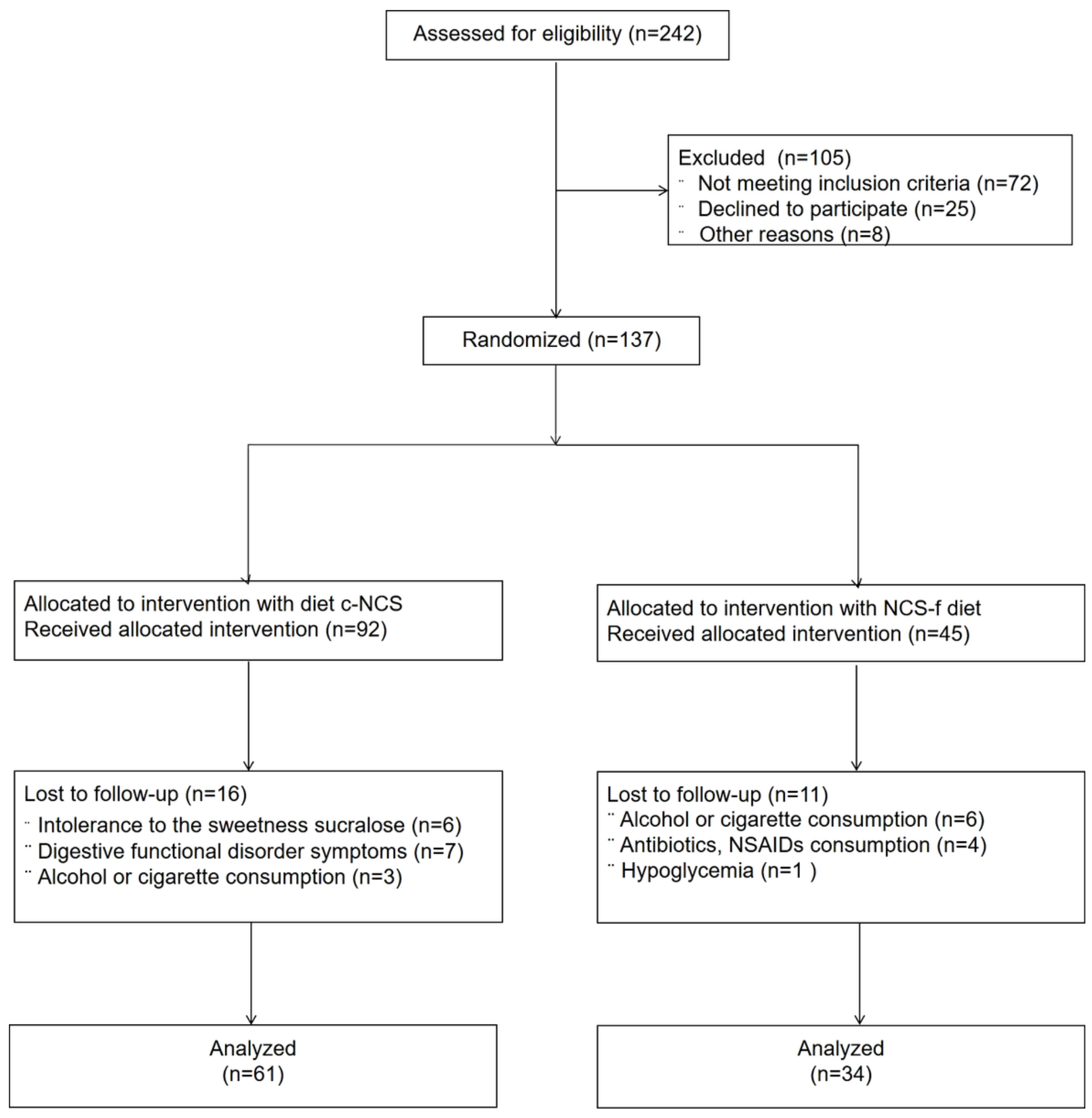

Figure 1

Flow chart according to CONSORT showing the process of recruitment, randomization, follow-up, and data analysis in the study. Adherence with FGDs: Functional Gastrointestinal Disorders symptoms, Food Frequency Questionnaire (FFQ), NCS Consumption Questionnaire (SCQ), and Bristol scale. Nonsteroidal anti-inflammatory drugs (NSAIDs). 
NCS-f Diet

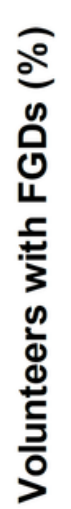

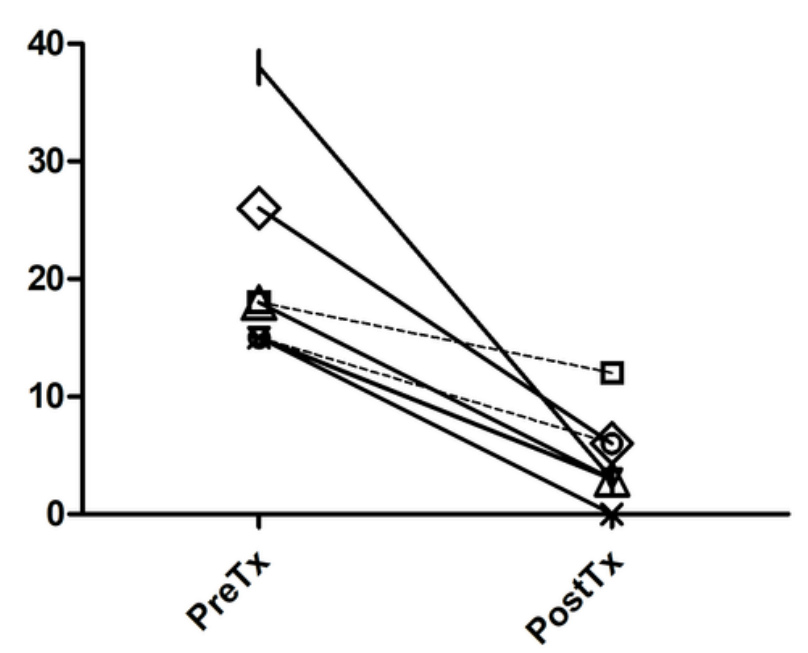

+ Epigastric Pain

$\nabla$ Abdominal Pain $\boxminus$ Constipation

O Diarrhea
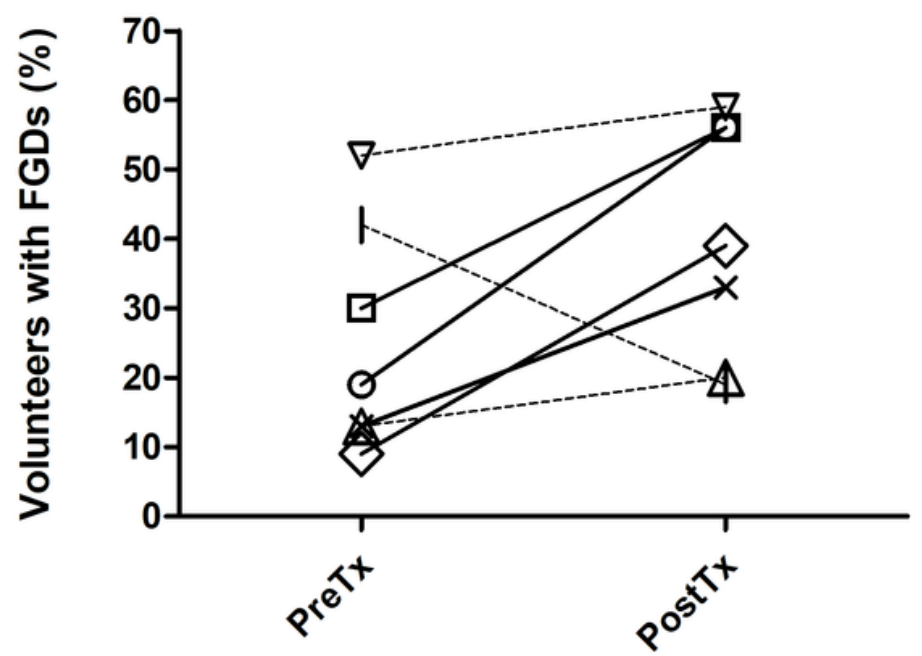

$\diamond$ Post-prandial discomfort

$\triangle$ Early Satiety

\section{Figure 2}

Functional Gastrointestinal Disorder symptoms at the beginning (PreTx) and at the end (PostTx) of dietary interventions with NCS restriction.

\section{Supplementary Files}

This is a list of supplementary files associated with this preprint. Click to download.

- CONSORT2010Checklist1.doc 